\title{
BETWEEN FASHION AND COSTUME DESIGN: ESTABLISHING SOCIAL AND HISTORICAL LINKS
}

B. AJIBADE AND E. OGBONNA

(Received 4 February 2005; Revision Accepted 13 June 2006)

\section{ABSTRACT}

Both fashion design and costume design are energetic aspects of visual design that have evident impacts upon man's everyday interactions in society. And from the basis that art affects society and society in turn affects art, this paper explores the social and historical contexts of both fashion and costume design. The paper outlines these two realms of artistic design, showing moments of transition where one can become the other The paper delineates how fashion can become costume and how costume can in turn become fashion. The social and historical means by which these transformations from costume to fashion (or vice versa) take place within the creative interaction of the artist, his/her design and the society are then articulated in the paper

\section{KEYNORDS: Fashion, Costume and Design}

\section{INTRODUCTION}

Fashion is a concept that implies change and acceptance of style in clothing and appareis. The term refers to designs of clothing or related objects that are in style at a particular time (Steele 2002). Because clothing tends to get out of fashion long before it has worn out, William Shakespeare poirited out, in the 16th century that "fashion wears out more apparel than the man."

In Shakespeare's day, and long after that, only the rich or upper-class dressed fashionably. Rural peasantry dressed in simple garbs that seemed never to change in style for several generations. Although changes in fashion have beer historically, the 20th ceritury witnessed a rapid change in fashion as in most other aspects of human culture. As technology evolved in capacity, efficiency and in the provision of newer materials it enabled aspects of diverse cultures to interact, irrespective of geographic and economic distances Such newer materials have enabled artists like fashion and costume designers to explore fresh creative avenues. Although fashion is an aspect of visual design, technology has played very crucial roles by evolving newer fabrics and accessories that the artist can employ. Technology also provides the media spaces of film, video, TV, satellite, print and Internet, through which fashion trends are distributed across the globe. Technology is thus a veritable vehicle for art and culture, and also of fashion.

Art is thought to reflect society and vice versa. And, since costume is an art form concerned with theatrical fabric and bodily apparels, it is conceivable that it has been directly impacted upon by the history of fashion or clothing design. Just as well, the social processes of fashion change are also impacted upon, sometimes, by the directions of theatrical or pertiormance costumes. For while fashion refers to popular social apparels of particular times, costume refers to contextual performance apparel whose very meaning and "time" placement is determined by the textual interpretation of specific dramatic or performative enactments. What may be historically true is that either fashion or costume can and do set the agenda for the evolution and acceptance of the other For instance, with the 20th century's revolutions in technology and media, performance stars have emerged as leaders of fashion (Steele 2002). This development is not delimited by spatial or cultural distances. Thus we find that the clothing or costumes of Hollywood stars - of TV, Cable/Satellite TV and cinema - have often determined the fashion of remote places like: Africa where these media events have audiences. In very plain terms, therefore, fashion affects costume and costumes in turn impacts upon fashion. This paper delineates the social and artistic interdependency, in historical terms, between fashion and costume design

Although Steel (2002) suggests that fashion reflects the society in which it exists, this much can also be said of costume. Fashion is influenced by several factors including wars, conquests. laws, religion, arts, societies and individual personalities. These factors are swifter to evidence today with the effectiveness of the ever-broadening contemporary technologies and the increased capacity for stronger cultures to impact upon weaker ones regardless of geographic distances. For instance, at the fall of the Taliban in Afghanistan, the people's sense of "fashion" changed drastically Western styled apparels including music, films and even the shaving of beards - hitherto prohibited by the ruling and extremist Taliban - became immediately fashionable among Afghans of all ages The long. obnoxious and abusive denial of the Afghan people's taste for the fashionable was particularly instrumental in the overwhelming acceptance and subsequent consumption of western fashion in the postTaliban years. This particular instance is an example of how war, law, and religion can affect fashion. For, religious extremism provided the inhuman laws that outlawed fashion in the first instance, only for war to provide social liberation and a foreign agenda for the consumption of fashion both as a product and as a vehicle of culture. Then, again, we remember that Afghanistan was denied access to the global media events before the fall of the Taliban. But with the renewed access to satellite TV and other global media programmes, a "western" agenda for a "new" Afghan fashion was then established, In other words, technology often enisures that the global not only destabilizes but also, sometimes, modifies or completely obliterates the local in terms of cultural production and consumption.

Whereas costume refers to performative appare fashion applies to everyday social contexts of fabric design uses. Unlike fashion costumes tend to elaborate styles and conventions of their own and are neither historical nor contemporary. In any performance context the director's interpretation and the 'spirit' of the event require certain emphasis on the designs of costume. Thus costume designs are either copies of period costumes or are positioned to evoke a certain historical period. The success of costumes in any event is largely dependent on the designer's understanding and interpretation of the director's production concept (Steele 2002). A "costume design is always linked to the character and life style envisaged by the playwright, as well as the human form of the actor" (Parker and Wolf 70). Whereas the script presents the character created by the author (in whatever style), character itself is interpreted by the actor and the design of the costume Thus the design of 
costume is one of the most vital aspects of performative arts In this context 'performance' is not limited to the theatre stage The term is also inclusive of $T \mathrm{~V}$, film and social contexts like academic convocations, marriages and burials where categories of people utilise special apparels. Costume use in performance, depending on the level of effectiveness, can place the action, provide compatible social atmospheres and stimulate audiences. It must be borne in mind that creative events like performance are exercises in specialisation. Thus a production design is split between a scene designer, a costume designer, a lighting designer and a sound designer, just as interior design projects might be split between an architect, a lighting designer, painter, sculptor, ceramist and the likes. These categories of designers bring their creativities together, working in very close collaboration with the director, to achieve a total visual effect and effective communication in any design project. In this context "visual effect" is determined by a corporate response to the script or artistic plan as decided by the "artistic team" (Parker and Woif 12). While it is true that fashion diffuses into the stage and becomes costume, it is the costume designer's unilateral skill that selects and blends fashion into a rigid interpretation of the script and the director's production concept. Where, for instance, the director's interpretation of a performance sequence places the action in, say, the 16th century, then the "fashion" of that time will generally constitute the "costume" of the present production By its ability to intrude in all spheres of human life fashion has a way of maintaining a creative hold over society But how exactly does fashion change and yet maintain a hold upon society?

Different cultures around the world have peculiar histories of fashion or clothing styles, which change for two prime reasons: (1) contacts with other societies and (2) competition for status within a society. These factors come very much to bear upon the production and consumption of fashion or clothing design. More than this, since final decisions about if or what to buy lies with the consumer, fashion does not succeed until people accept it (Steele 2002). What is evident here is that "fashion" is not an exclusive concept but an inclusive one that derives its legitimacy from mass acceptance or popularity among a given people

Fashion also tends to tow behind social and economic power. Fashion is definitely a social signifier. Like in many African societies, the European social systern was able (through sumptuary laws) to reaffirm and preserve the distinctions between the peasant, middle class (bourgeoisie) and the aristocratic dresses. Many African societies like the Edo of Nigeria have regulations concerning how peasants, chiefs and kings dressed. This then signifies a parallel trend in the history of fashion and costume in both Africa and Europe. In France, the 1789-99 Revolution brought an end to sumptuary laws and replaced them with a new freedom of dress (Steele 2002) Although Africa may not have had outright revolutions, economic and social dynamics have made traditional class-sensitive dressing obsolete. As the histories of France and the rest of Europe have shown, economic power generates in the middle class the tendency to want to equate the upper class in politics and in clothing After appropriation such exclusive aristocratic dress-forms thus diffuse into and are "popularized" in the realms of the populous middle class. At the point of the acceptance of these formerly aristocratic dress forms they become "fashion." Thus social and economic status was most paramount in the establishment of leadership in fashion. But in today's technocratic world, celebrity and star systems in the global media are more significant in establishing fashion leadership than social status. For dresses worn by Hollywood's cream of stars have continuously influenced giobal fashions even where severe economic disparities exist. As we find in campuses of Nigerian Universities, fashion is directly moderated by Hollywood images found in films and musicals. And we find, for instance, that though campus fashion in Nigeria is quite expensive, students from ostensibly poor backgrounds find desperate means to acquire fashions gleaned from global media. This validates the point that, through the global media industry, PR and advertising multinationals use actors, musicians and sport personalities to lunch or popularize new fashions and accessories (Steele 2002). Whereas people normally construe "fashion" to include dresses, the term also embodies jewellety and other adornments including cars, walking sticks and even mobile phones. These items of utility are "endorsed" by personalities and sold to consumers through corporate advertising and marketing strategies as "new fashion." One critical thing is that the global (but western) media, through very subtle appeals, is abie also to create needs among unsuspecting consumers in non-western societies. By the creation of this felt need and viable consumerism in distant lands by the western media, an ever-increasing global market is thus sustained for the marketing of western fashion first to the local Elites and leaders of sorts. And by aspiration and the quest for social equality the middle and lower classes appropriate it from the exclusive class. Once these populous lower classes adopt the products they certainly become "fashion"

Two critical events, global democratization and the advancement in technology, have impacted upon the development of fashion. The idea that all men were equal was promoted by both the French and American revolutions. This spirit of democracy gradually ensured that clothing changed to reflect this newfound equality Before this, rigid monopolies were maintained by the upper/aristocratic class over luxurious clothing. This meant that serious distinctions in the quality of cloth and ornamentation worn by both classes were maintained And, no matter how rich a commoner got, through handwork, he could neither acquire nor garb himself in clothes befitting of the upper class in the post-revolution France, clothing became a monumental symbol of equality rather than of social status. And, even in England plainer and simple clothing was perceived as more natural and more democratic (Steele 2002)

Technological advancements have also ensured that affordable "fashion" is made avallable to the middle class. The development of synthetıc fabric dyes popularized bright colours. These came to replace the previously fashionable pastel colours achieved by natural dyes. Isaac Singer's improvements upon the sewing machıne (patented in 1846) made fashion production faster and cheaper. This led to the affordable mass production of styles previously ascribed to the wealthy. Also, in 1801, the Jacquard $100 \mathrm{~m}$ was perfected by the inventor, Joseph-Marie Jacquard. This device both automated a bulk of the fabric-weaving patterns and also made a great deal of variety possible (Steele 2002)

One other area where technology has advanced the growth of fashion is the iact that global distances have been bridged and cultures are no longer self-contained. The 20th century witnessed far reaching moves towards cultural homogenization where interaction among people enabled them to acquire aspects of foreign cultures. Global travel became easier and faster, multinational media penetrated former hinterlands; and popular culture assumed a global dimension in terms of musıc entertaınment, fashion and general consumerism. The freedom of dress wrought by the American (1775-1783) and French (1789-1799) revolutions gradually spread to other parts of the globe. And, democratization and technology ensured that people were able to acquire whatever clothing they desired, so long as they could afford it. People were no longer bound to rigid codes in dressing. By the end of the 20th century the inspiration for individual fashions was evidently drawn from history and from distant global locales and cultures. This saw the appropriation of non-western clothing - fabrics, adornments, jewellery, shawls etc - from African and Asian sub-continents into global fashion and production parlance. Paris has been an important global fashion market, where names like Coco Channel, Paul 
Poiret, Madeleine Vionnet, Christian Dior, Yves Saint Laurent Chloe etc have made historical landmarks. Fashion has been produced and consumed on two levels in Paris. First is the haute couture (fine dressmaking), which was established by custom dressmakers called couturiers designers of custommade wears. They produce very expensive fashions

The second level is the pret-a-porter (ready-to-wear) clothes designed and mass produced by createurs (creators) as different from couturiers (Steele 2002). Whereas prêt-aporter clothes could cost a few collars, haute couture runs into several hundreds or thousands in value. Today, ready-made clothing is a multimillion-dollar global industry (Bevlin 1983) This global ready-made market is sustained by the fact that people are increasingly becoming visually literate and fashion conscious in their daily business of living. This has continued to prompt people to increasingly bother about how they look and what they wear. And, with the growth of department stores in nearly all societies consumers are afforded the opportunity of veriety in retail buying. What is ciear is that individuality has become the norm in fashion well beyond the 20th century. By the 21st century it has become possible not just for people to decide what to wear but also how to wear its that is, without any reference to institutional or stringent social class systems.

The result is that one could find several people wearing a particular "fashion" but in several individual ways. Individualism has become a mark of contemporary global fashion. This was not always so in the history of the social struitures of diverse global cultures. In Europe what was formerly the norm - rigid and codified dress modes based on social class rather than personal choice and individualism gave way to rebellien in the World War I (1914-1918) yearrs onwards. The war did not just weaken former social structures but led younger generations to rebel against the wisdom of their elders (Steele 2002). This marked the birh of radical and individualistic fashion in terms of makeup, hair cut and flimsier clothing

World War II (1939.41) brought with it the rise of casuals as everyday wear across Europe. In the post-World War years fashion became a big global business and, by the 196ios, youthfulness was the dominant theme of the fastexplanding fashion business. The first phase of this 1960-move wa:s called mod (short for modern) fashion in which synthetics miriskirts and wet-look took centre stage The second phase was the hippie look by which young people criticized conformity and consumerism with ethnic and retro (backwardlooking) clothing that were based on non-western garments (Steele 2002).

One fact that remains historicaliy true of fashion is that it is cyclical. That is, long forgotten styles can and do become fashionable again with time. For instance, ancient Greek and Roman inspiration was derived in the later 18 th century for a dress called Chemise. It was aimed at the preFrench revolution styles. The dress was ostentatious and overly ornate (Steele 2002). After years of dormancy the chemise dress was launched again in the late 1950s. Another example is the blue jeans, which was invented by Levi Strauss \& Co in 1873 as work clothing for labourers. By the 1960 s blue jeans became not just the symbol of nonconformity and youth culture but also one of the most important garments, in popular society. Well into the 21st century, jeans still retains its hold on global popular culture, howbeit, in various shades of colour. In Nigeria mini and tight skirts, including high-heeled shoes, fashionable in the 60s and 70s, found their way back into popular fashion by the close of the 20th century. Today these apparels are worn with reckless abandon by Nigerians of all economic categories. Fundamentally, any of "the aforementioned clothing of any perico in man's history can bacome costume in the context of performance. The moment a piece of fashion is taken out of its social parameters into a performance context it becomes costume. And, in the same vein when a costume is taken out of its performance contexts and into popular social applications it becomes fashion. It is therefore not a matter of design or style but of functional contexts that spell the vital difference between fashion and costume. The same fabric or apparel, depending on its functional application, can be interpreted as either fashion or costume.

The discussion so far has taken us through a historical and social overview of fashion. and the highpoint of dressmaking. And these key points have emerged from the discourse so far:

1. That fashion refers to clothing that is in style at a given time

2. That fashion refers to clothing styles that are popular

3. That fashion does not merely change but also exists in a cyclic nature - coming back into vogue many years after it has died out

4. That fashion is a culture product and thus. is reflective of social dynamics of the society that gives it birth.

5. That the fashion of any one period can depending on several variables, become costume - just as well as the costume worn by a star can become fashion

It should however be noted here that the line distinguishing costume and fashion are not always and necessarily very clear. For, it is possible that a piece of apparel is both costume and fashion at the same time. We may draw two examples to show this: wedding gowns and academic convocation gowns (particularly PhD). In every respect both instances of marriage and academic convocations are ritualised ceremonies - full of drama and performance requiring unique costumes. The manner in which these costumes are made and worn at any one instance is however determined by factors such as individual taste. social trends, economic class etc, which insert these apparels into the glittering grip of modernity. At these ceremonies, individuals use various fabrics and motifs to design their own versions of the archetypal attires to make clear social statements about who they are and how 'modern' and 'trendy' Wedding gowns are, for instance, cut to the dictates of contemporary fashionable trends - the same can be said of the groom's suit. which, these days in Nigeria, are trendily made. In the convocation gown, we find a lot of would-be post-graduates sewing and customising the ir institutional gowns in the trendiest possible ways. People use applique, trimmings, special buttons, iight-sensitive fabrics, etc, to make clear fashion statements. In the respect of the foregoing, wedding dresses and academic convocation gowns - which are institutional costumes - are also ostensibly fashions, in every sense of the term.

The history of costume or theatrical apparel shows that as with ancient fashion, styles were customized to fit into aesthetic frames that approximated rigid social classes as a way of placing the action for the audience. For instance the Onkos that surmounted Greek performance masks symbolized the character's social status. And, in Roman drama, costumes were also class-sensitive (Trip and Barker 2003). Beads walking sticks, caps of various colours etc are used to signify sociai difference in Africa too. Medieval mystery/morality plays and Renarssance performances utilized costumes cast in the rigid social frame of the various periods: But, in the late 1500 s in England, costumes that mixed styles and periods were used without particular attention to character and historical accuracy (Trip and Barker 2003) The cosiume of the Baroque and early 18 th century was also complex and heavily ornate. By the later half of the 1700 s French actors Henri-Louis Lelain, Mile Clairon and Francois-Joseph Talma, including David Garrick of England and the Irish Charles Macklin began to use costumes that were simple, realistic and histoncally accurate. By the mid 1800 s the effects of Rornantism - elaborate detailed stage settings and costumes - were heavy upon the uncoordinated theatre. Dissatisfied with this, the Duke of Saxe-Meiningen 
designed his own productions and became the first director to achieve a coordinated and integrated production between performance and technical/visual aspects like costuming (Trip and Barker 2003). But the drift from heavy ornamentation to milder design in social practice and performance is also evident in African societies. Archaeological findings indicate the gradual de-ornamentation of Nok, Ife and Benin sculptures. In the same vein, previously heavy decorations of wedding and burial ceremonies in many parts of Nigeria have given way to more subtle but ostensibly western fashions.

The 20th century saw a lot of experimentation in costume and performance design. Prominent names in this experimental period include Meyerhold, Merce Cunningham, Alwin Nilolasi, Brecht and Jerzy Grotowski, from whom contemporary costume and fashion design have benefited immensely. Thus, aside from the fact that the fashion of any historical era is a rich inspiration for costume design, technological advancement has enabled the clothing industry to evolve an endless array of synthetic fabrics. This has been a wonderful development for both costume and fashion design It has meant that the costumier and the fashion designer have been availed limitless choices in fabric properties in the execution of their arts. And, that, because of the developments in fashion and technology it is now possible for the costume designer to achieve every imaginable effect on stage since it is now possible to source special clothing like asbestos fabrics or those that react to specific stimulus like heat, light, air and moisture. This fact has greatly increased the visual and dramatic qualities attainable by the fashion and costume designer. Creative and social contexts of fashion and costume design are then more fulfilling and performative contexts more real, more convincing, and more captivating for contemporary audiences of visual arts. Owing to the social, historical and creative links between costume and fashion, a costume designer must understand not just the dynamics of fashion but also the processes of textile production, from fibre to fabric and fabric decorations. For instance, wool, cotton, silk and linen (natural fibres) were the materials from which fabrics and fashionable clothing were made before the advent of synthetics. But technological advancements have provided synthetic fibres such as polyester, cellulose triacetate and acrylics are in use today (Ekpe 2002). This has broadened the range of fabrics available for the design of costumes and fashion wares. Fashion and costume thus have historical and social linkages that tend to moderate or vitalise one with the attributes of the other at different times and places. Such cross-vitalities are necessary for sustaining either fashion or costume in the contexts culture production and consumption. Technology is therefore the bridge and the facilitator between the designer and the society on the one hand, and fashion, costume and their social contexts of use, on the other.

\section{REFERENCES}

Bevlin, M. E., 1984. Design through Discovery. Fourth Edition. New York: Holt

Ekpe, U., 2002. "Introduction to Textiles." Creative and Media Arts: A Practical Source Book. Eds. Babson Ajibade and Efiong Omini. Calabar: Baaj, 113-123.

The Focal Encyclopedia of Film and Television Techniques, 1973. London: Focal

Parker, W. O. and Craig R. W., 1996. Scenic Design and Stage Lighting. Seventh Edition. Orlando: Harcourt,

Steele, V., 2002. "Fashion". Encarta Encyclopedia 2002. CD ROM. Microsoft.

Tripp, H. and Clive B., 2003. "Stage design". Encyclopedia Britannica. CD ROM. Chicago; Encyclopedia Britannica Inc. 